\title{
Signal amplification of dopamine using lanthanum hexacyanoferrate-modified electrode
}

\author{
T SELVARAJU ${ }^{\mathrm{a}, \mathrm{b}, *}$ and R RAMARAJ ${ }^{\mathrm{a}}$ \\ ${ }^{a}$ Centre for Photoelectrochemistry, School of Chemistry, Madurai Kamaraj University, Madurai 625021 , India \\ ${ }^{b}$ Department of Chemistry, Karunya University, Coimbatore 641 114, India \\ e-mail: selvaraju@karunya.edu
}

MS received 31 January 2012; revised 12 September 2013; accepted 14 October 2013

\begin{abstract}
A sensitive and selective electrochemical sensor has been developed using an electroactive polynuclear lanthanum hexacyanoferrate (LaHCF) complex with counter alkali cation $\left(\mathrm{Na}^{+}\right)$deposited on the glassy carbon (GC) electrode (GC/LaHCF). The GC/LaHCF-modified electrode is found to be an excellent transducer in mediating the oxidation of neurotransmitter molecule such as dopamine (DA) at physiological $\mathrm{pH}$ 7.2. Interestingly, the GC/LaHCF-modified electrode amplifies a 50-fold enhancement in the oxidation of DA signal compared to the bare GC electrode. Besides, the GC/LaHCF-modified electrode shows excellent selectivity in the voltammetric oxidation of DA in the presence of ascorbic acid (AA). Under optimal conditions, the GC/LaHCF modified electrode shows a linear relationship in DA oxidation between $0.1 \times 10^{-6}$ and $1.0 \times$ $10^{-6} \mathrm{M}$ with the detection limit of $1 \times 10^{-8} \mathrm{M}(10 \mathrm{nM})$. Importantly, practical utility of the modified electrode is good in studying the real sample analysis such as dopamine hydrochloride injection assay.
\end{abstract}

Keywords. Lanthanum hexacyanoferrate-modified electrode; dopamine; ascorbic acid; signal amplification; real sample analysis.

\section{Introduction}

Prussian blue (PB) and its analogues which belong to a class of polynuclear inorganic compounds and resemble redox organic polymers and zeolitic or intercalation materials are studied extensively in various applications. ${ }^{1-17}$ Although, transition metal hexacyanoferrate series are exploited to a greater extent, limited studies are conducted on the properties and applications of rare earth metal hexacyanoferrates, for e.g., lanthanum hexacyanoferrate, etc. ${ }^{9,18,19}$ Lanthanum finds potential applications in hydrogen storage materials, ionselective electrodes, chemical sensors, electrocatalytic hydrogenation of organic substrates and as a promoter to facilitate the electrochemical reactions of biological molecules. ${ }^{9,10}$ In general, the deposition of highly stable film on the electrode surface is a major criterion in various applications. ${ }^{10-17}$ Liu et al. have introduced two new $\mathrm{PB}$ analogues, namely zirconium hexacyanoferrate $\left.^{20,21}\left(\mathrm{~K}_{\mathrm{Z}} \mathrm{Zr}_{3}(\mathrm{OH})_{6} \mathrm{Cl}_{3}\right] \mathrm{Fe}(\mathrm{CN})_{6}\right)$ and lanthanum

*For correspondence hexacyanoferrate ${ }^{9}\left(\mathrm{Na}^{+} \mathrm{La}^{3+}\left[\mathrm{Fe}^{\mathrm{II}}(\mathrm{CN})_{6}\right]\right)(\mathrm{LaHCF})$, in solid-state electrochemistry. It reveals that the small channels of LaHCF lattice were unable to accommodate alkali metal cations and no obvious voltammetric response was observed in the supporting electrolyte such as $\mathrm{NaCl}$ and poor performance in the presence of $\mathrm{KCl}^{9}{ }^{9}$ Wang et al. have used lanthanum hexacyanoferrate-modified electrode in the determination of uric acid in the presence of AA, whereas the voltammetric response was very poor in the presence of $\mathrm{KCl}^{22}$ On the other hand, in the present study, LaHCF on glassy carbon (GC) electrode surface shows a very good voltammetric response in the presence of $\mathrm{NaCl}$.

DA is one of the most significant catecholamines which belong to the family of excitatory chemical neurotransmitters. It plays a very important role in functioning the central nervous, cardiovascular, renal and hormonal systems, as well as drug addiction and Parkinson's disease. ${ }^{23-25}$ DA and AA usually coexist in the human biological system and undergo electro oxidation in the same potential which results in overlapping voltammetric responses making their discrimination highly difficult. ${ }^{26,27}$ Thus, the determination of submicromolar concentration of DA in the presence 
of interferences has gained much attention. ${ }^{23-30}$ The conducting polymer incorporated metal hexacyanoferrates show poor selectivity towards DA determination. ${ }^{31,32}$ Cobalt hexacyanoferrate-modified electrodes, ${ }^{13,14,33}$ Th(IV)-hexacyanoferrate-modified electrodes ${ }^{34}$ and ruthenium hexacyanoferrate-modified electrodes ${ }^{35}$ were used to study the high concentrations of DA. Besides, nickel hexacyanoferrate, ${ }^{36,37}$ silver hexacyanoferrate $^{38}$ and tin hexacyanoferrate-modified ${ }^{39}$ electrodes were studied at slightly higher concentrations of DA. In the absence of inference such as AA, neodymium hexacyanoferrate-modified electrode was used to study DA. ${ }^{40}$ To the best of our knowledge, there is no report on the electrochemical investigation of lanthanum hexacyanoferrates towards the oxidation of neurotransmitter molecule such as DA. In the present study, first, the preparation and electrochemical characterization of LaHCF-modified GC electrode in the presence of $\mathrm{NaCl}$ are highlighted. Secondly, the signal amplification towards DA oxidation is justified and the estimation of DA in the presence of AA, is discussed, at the GC/LaHCF-modified electrode. Finally, a simple and robust amperometric read-out is tabulated for real sample analysis such as dopamine hydrochloride injection solution using this modified electrode.

\section{Experimental}

Lanthanum chloride, dopamine hydrochloride, ascorbic acid and potassium hexacyanoferrate (Merck) were used without any further purification. All other chemicals were of analytical grade and used as received. Freshly prepared solutions of DA and AA were used in all experiments. Phosphate buffer solution $(0.1 \mathrm{M}$, $\mathrm{pH}$ 7.2) was prepared using $\mathrm{Na}_{2} \mathrm{HPO}_{4} \cdot 12 \mathrm{H}_{2} \mathrm{O}$ and $\mathrm{NaH}_{2} \mathrm{PO}_{4} \cdot 2 \mathrm{H}_{2} \mathrm{O}$ (Merck) stock solutions. All solutions were prepared using doubly distilled water.

Electrochemical experiments were performed with an EG\&G PAR model 283 potentiostat/galvanostat controlled by Echem software loaded personal computer. The electrochemical measurements were carried out with a two-compartment three-electrode cell, containing platinum wire as a counter electrode, standard calomel electrode (SCE) as a reference electrode and glassy carbon ( $\mathrm{CH}$ Instruments Inc.) or modified GC electrode as a working electrode $\left(0.07 \mathrm{~cm}^{2}\right)$. Prior to each experiment, the GC electrode was polished with the slurries of 0.3 and $0.05 \mu \mathrm{m}$ alumina to a mirror finish and rinsed using doubly distilled water. Then, the electrodes were ultrasonicated in doubly distilled water for about $2 \mathrm{~min}$. Finally, the electrode was activated by cycling between -0.2 and $0.8 \mathrm{~V}$ in $0.1 \mathrm{M} \mathrm{KCl}$ at a scan rate of $50 \mathrm{mV} \mathrm{s}^{-1}$ in order to get a stable cyclic voltammogram. In this study, all the potentials were quoted against SCE.

The GC/LaHCF-modified electrode was prepared using freshly prepared equimolar mixture of $10 \mathrm{mM}$ $\mathrm{LaCl}_{3}$ and $10 \mathrm{mM} \mathrm{K}_{3} \mathrm{Fe}(\mathrm{CN})_{6}$ solution containing $0.3 \mathrm{M}$ $\mathrm{NaCl}$ by potential cycling between $0.8 \mathrm{~V}$ and $-0.2 \mathrm{~V}$ at a scan rate of $50 \mathrm{mV} \mathrm{s}^{-1}$ for 20 cycles. The LaHCF was found to grow on the surface of the GC electrode with respect to a number of potential cycles. Finally, the electrode was washed with distilled water and used in voltammetric applications.

\section{Results and discussion}

\subsection{Electrosynthesis of LaHCF on GC electrode}

The GC/LaHCF-modified electrode was prepared by cycling the potential between $0.8 \mathrm{~V}$ and $-0.2 \mathrm{~V}$ at a scan rate of $50 \mathrm{mV} \mathrm{s}^{-1}$ in $0.3 \mathrm{M} \mathrm{NaCl}$ solution containing an equimolar mixture of $10 \mathrm{mM} \mathrm{LaCl}_{3}$ and $10 \mathrm{mM}$ $\mathrm{K}_{3} \mathrm{Fe}(\mathrm{CN})_{6}$. Figure 1 shows the continuous cyclic voltammograms recorded during LaHCF film formation on the GC electrode. During electrosynthesis, the redox peak current was decreased gradually with respect to potential cycling (figure 1). Thus, in the electrosynthesis process, it is understood that there are two steps involved in the generation of LaHCF on the electrode surface (eqs 1 and 2). The first step is the electroreduction of $\left[\mathrm{Fe}^{\mathrm{III}}(\mathrm{CN})_{6}\right]^{3-}$ to $\left[\mathrm{Fe}^{\mathrm{II}}(\mathrm{CN})_{6}\right]^{4-}$. Instantaneously, the reduced $\left[\mathrm{Fe}(\mathrm{CN})_{6}\right]^{4-}$ forms a

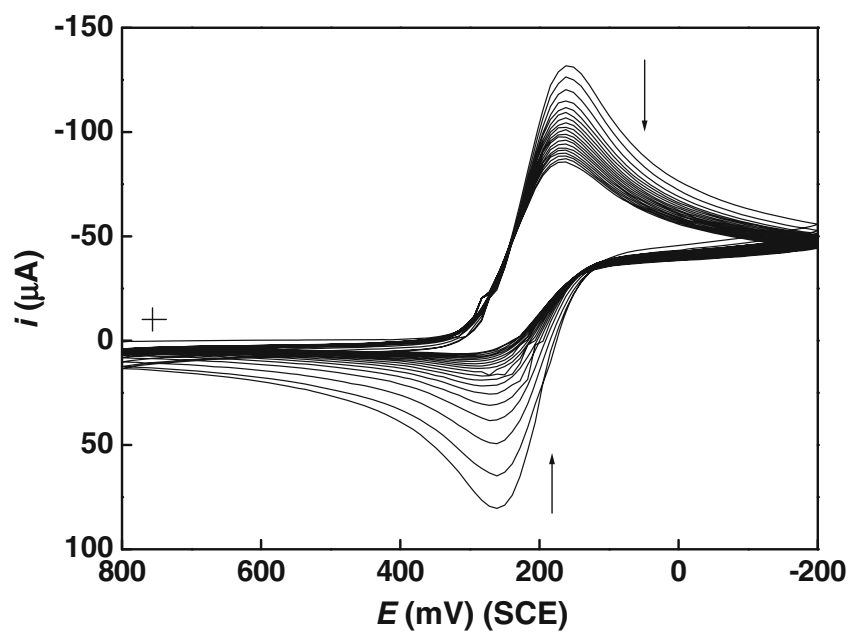

Figure 1. Continuous $\mathrm{CV}$ s recorded during electrosynthesis of $\mathrm{LaHCF}$ on $\mathrm{GC}$ electrode using $10 \mathrm{mM} \mathrm{LaCl} 3,10 \mathrm{mM}$ $\mathrm{K}_{3} \mathrm{Fe}(\mathrm{CN})_{6}$ and $0.3 \mathrm{M} \mathrm{NaCl}$. Number of cycles $=20$. Scan rate $=50 \mathrm{mV} \mathrm{s}^{-1}$. 
complex with $\mathrm{La}^{3+}$ ion, which is a chemical reaction that firmly deposited as sodium lanthanum hexacyano-
ferrate(II) $\left(\mathrm{Na}^{+} \mathrm{La}^{3+}\left[\mathrm{Fe}^{\mathrm{II}}(\mathrm{CN})_{6}\right]\right)$ on the surface of the GC electrode. ${ }^{9}$

$$
\begin{gathered}
{\left[\mathrm{Fe}^{\mathrm{III}}(\mathrm{CN})_{6}\right]^{3-}+\mathrm{e}^{-} \longrightarrow\left[\mathrm{Fe}^{\mathrm{II}}(\mathrm{CN})_{6}\right]^{4-}(\text { Electrochemical reaction })} \\
{\left[\mathrm{Fe}^{\mathrm{II}}(\mathrm{CN})_{6}\right]^{4-}+\mathrm{La}^{3+}+\mathrm{Na}^{+}+\mathrm{nH}_{2} \mathrm{O} \longrightarrow \mathrm{Na}^{+} \mathrm{La}^{3+}\left[\mathrm{Fe}^{\mathrm{II}}(\mathrm{CN})_{6}\right] \cdot \mathrm{nH}_{2} \mathrm{O}(\text { Chemical reaction })}
\end{gathered}
$$

Voltammetric characteristics of the LaHCF film formation process at the electrode surface are different from the electrochemically deposited transition metal hexacyanoferrates such as cobalt hexacyanoferrate, ${ }^{41}$ nickel hexacyanoferrate ${ }^{41}$ and the mixed hexacyanoferrates of nickel and palladium. ${ }^{33,42,43}$ In the electrosynthesis process of transition metal hexacyanoferrates, the peak current increases with an increase in the number of potential cycles and attained saturation; whereas in the case of inner transition metal hexacyanoferrate, LaHCF, the behaviour is quite different. Here, the redox peak current decreases which is due to electrochemical reaction followed by a chemical reaction (eqs 1 and 2) which takes place during LaHCF film formation. Accordingly, the free $\left[\mathrm{Fe}^{\mathrm{III}}(\mathrm{CN})_{6}\right]^{3-}$ hardly gets deposited on the electrode surface, whereas it tends to reduce as $\left[\mathrm{Fe}^{\mathrm{II}}(\mathrm{CN})_{6}\right]^{4-}$, and besides in the presence of $\mathrm{La}^{3+}$, it forms LaHCF complex on the electrode surface (eqs 1 and 2). During LaHCF formation, these two-step reactions lead to a gradual decrease in the redox peak current. In order to form a stable LaHCF film with good transport and conducting properties, the electrosynthesis process requires a relatively high concentration of precursors such as $\mathrm{LaCl}_{3}(\sim 10 \mathrm{mM})$ and $\mathrm{K}_{3} \mathrm{Fe}(\mathrm{CN})_{6}(\sim 10 \mathrm{mM})$. It is well-known that the film formation of transition metal hexacyanoferrates on the electrode surface is rapid in a solution of low concentration $(\sim 0.5 \mathrm{mM}) .{ }^{33,41-43}$ On the other hand, our experimental results indicate that the LaHCF film formation was observed at relatively high concentrations of precursors. The observed result is justified by eqs 1 and 2 .

\subsection{Electrochemical characterization of GC/LaHCF electrode}

Cyclic voltammograms of the GC/LaHCF electrode were recorded in the presence of a solution containing $0.3 \mathrm{M} \mathrm{NaCl}$ and $0.1 \mathrm{M} \mathrm{HCl}$ at various scan rates (figure 2). The observed $E_{1 / 2}$ value $(0.31 \mathrm{~V})$ and the peak separation potential $\left(\Delta E_{\mathrm{p}}=60 \mathrm{mV}\right)$, are almost independent of scan rates in the range of $10-100 \mathrm{mV} \mathrm{s}^{-1}$. Anodic and cathodic peak currents are increase linearly with the square root of scan rate (figure 3 inset) indicating that diffusion-controlled electron transfer process is observed at the LaHCF-modified electrode. It is established that the simultaneous motion of counter cations such as $\mathrm{Na}^{+}, \mathrm{K}^{+}$, etc., occur to attain an electroneutrality during the electrochemical reaction of metal hexacyanoferrates. ${ }^{9}$ Eventually, the formal potential of LaHCF is noted as more negative than that of the transition metal hexacyanoferrates such as cobalt and nickel hexacyanoferrates. ${ }^{41}$

\subsection{Signal amplification of DA oxidation at GC/LaHCF modified electrode}

Figure 3 shows the cyclic voltammograms recorded for the GC/LaHCF electrode in $0.1 \mathrm{M}$ phosphate buffer $(\mathrm{pH} 7.2)$ at a scan rate of $50 \mathrm{mV} \mathrm{s}^{-1}$ in the absence and presence of $0.1 \mathrm{M} \mathrm{NaCl}$. Redox behaviour of the GC/LaHCF-modified electrode gets improved in the presence of $\mathrm{Na}^{+}$ions with an $E_{1 / 2}$ at $0.2 \mathrm{~V}$. To

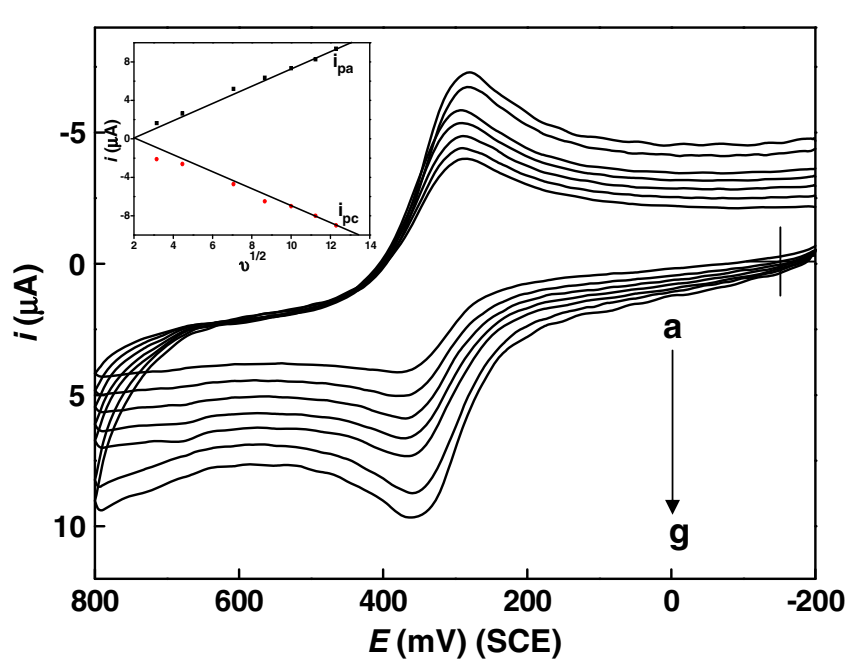

Figure 2. CVs obtained at GC/LaHCF electrode in a mixture of $0.3 \mathrm{M} \mathrm{NaCl}$ and $0.1 \mathrm{M} \mathrm{HCl}$ at various scan rates. The scan rates are: $a=10, b=20, c=50, d=75, e=100, f=$ 125 and $g=150 \mathrm{mV} \mathrm{s}^{-1}$. The inset shows the dependence of anodic and cathodic peak currents against square root of scan rate. 


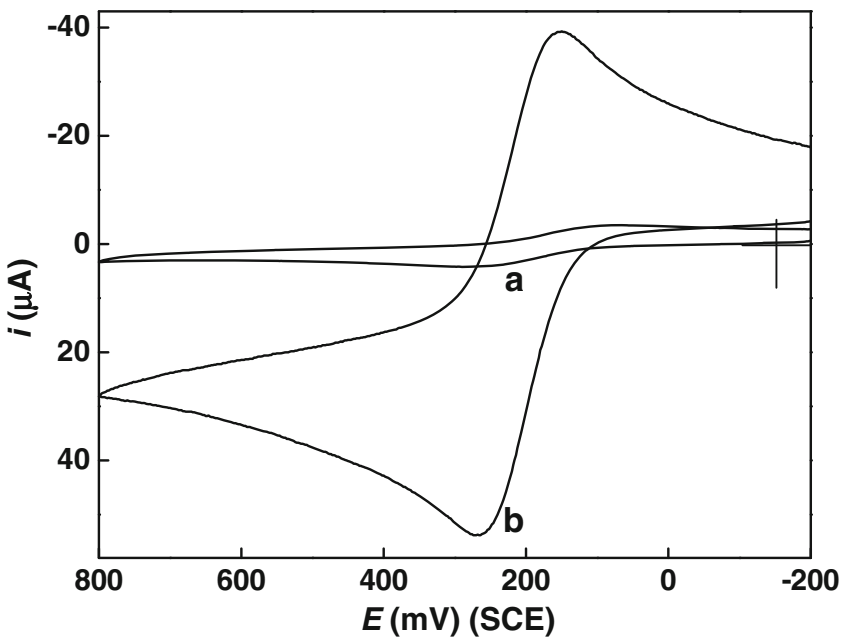

Figure 3. CVs obtained at $\mathrm{GC} / \mathrm{LaHCF}$ modified electrode in $0.1 \mathrm{M}$ phosphate buffer in the absence (a) and presence (b) of $0.1 \mathrm{M} \mathrm{NaCl}$. Scan rate $=50 \mathrm{mV} \mathrm{s}^{-1}$.

the best of our knowledge, this type of excellent quasi-reversible cyclic voltammetric response is not yet reported for lanthanum hexacyanoferrate-modified electrode. Influence of anions on the electroactivity of metal hexacyanoferrates has been described elsewhere. ${ }^{44,45}$ However, it seems implausible that adding chlorides might cause the observed massive increase in the peak current. In the present study, the reduced form of LaHCF could amplify the oxidation signal of biologically important neurotransmitter molecule such as DA. To investigate the electron-mediating activity of the GC/LaHCF-modified electrode, DA oxidation was studied. Figure 4 shows cyclic voltammograms recorded for the GC/LaHCF-modified electrode both in the absence and presence of DA. A stupendous increase in the oxidation peak current is observed for DA at the GC/LaHCF electrode (figure 4b) compared to the absence of DA (figure 4a). On the other hand, a significant peak current is not observed for DA at the bare GC electrode as shown in figure 4(inset). Thus a 50-fold enhancement in the peak current towards DA oxidation is observed at the LaHCF-modified electrode compared to the bare GC electrode. It means that the promotional effect of LaHCF is the basis for the high electron facilitating activity towards DA oxidation. Schematic representation of DA oxidation by the LaHCF $\left(\mathrm{Na}^{+} \mathrm{La}^{3+}\left[\mathrm{Fe}^{\mathrm{II}}(\mathrm{CN})_{6}\right]\right)$-modified electrode is shown in figure 5. A similar kind of observation was recorded at the superoxide dismutases-modified electrode. ${ }^{46}$

Figure 6 shows the differential pulse voltammograms (DPV) recorded for different concentrations of

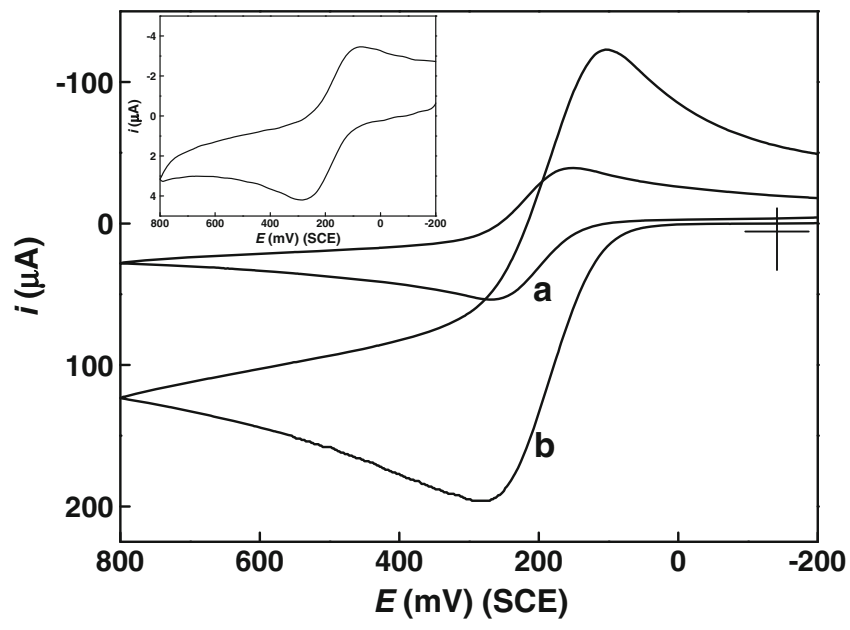

Figure 4. $\mathrm{CV}$ s obtained at $\mathrm{GC} / \mathrm{LaHCF}$ electrode in $0.1 \mathrm{M}$ phosphate buffer containing $0.1 \mathrm{M} \mathrm{NaCl}$ in the absence (a) and presence (b) of $10 \mu \mathrm{M}$ DA. Inset shows the $\mathrm{CV}$ of $10 \mu \mathrm{M} \mathrm{DA}$ at bare GC electrode in $0.1 \mathrm{M}$ phosphate buffer containing $0.1 \mathrm{M} \mathrm{NaCl}$. Scan rate $=50 \mathrm{mV} \mathrm{s}^{-1}$.

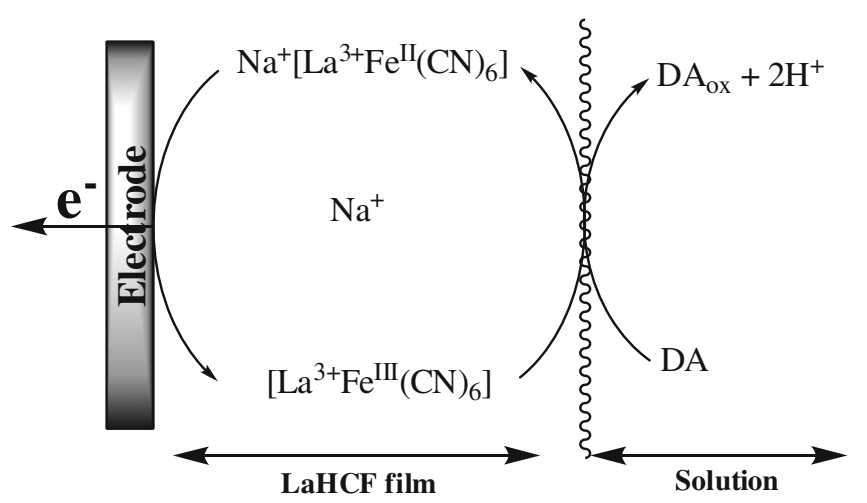

Figure 5. Schematic representation of electrooxidation of $\mathrm{DA}$ at the GC/LAHCF electrode.

DA at the GC/LaHCF electrode. The DPV peaks are well-defined and the peak currents are proportional to the [DA] and increase linearly with increasing DA concentration (figure 6 inset) with a correlation coefficient of 0.997. When compared to bare GC electrode, the DPV shows a significant amplification in the anodic peak current due to DA oxidation at the GC/LaHCF electrode. Detection limit of DA at the GC/LaHCFmodified electrode is calculated as $10 \mathrm{nM}$ at a signalto-noise ratio of 3 . After 10 repetitive cycles, no significant losses in the anodic peak current are observed for DA oxidation at the modified electrode.

\subsection{Selective oxidation of $D A$ in the presence of $A A$}

The modified electrode should possess selectivity towards DA oxidation in the presence of interferences 


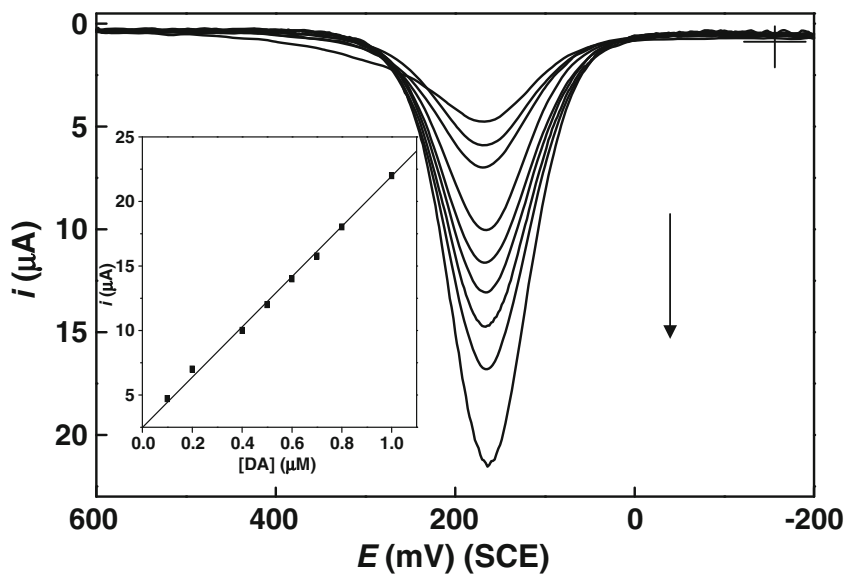

Figure 6. DPVs obtained at GC/LaHCF electrode in $0.1 \mathrm{M}$ phosphate buffer containing $0.1 \mathrm{M} \mathrm{NaCl}$ in the presence of different $[\mathrm{DA}]$. Scan rate $=5 \mathrm{mV} \mathrm{s}^{-1}$. $[\mathrm{DA}]=0,0.1,0.2$, $0.4,0.5,0.6,0.7,0.8$ and $1.0 \mu \mathrm{M}$. Inset depicts the plot of peak current $v s$. [DA].

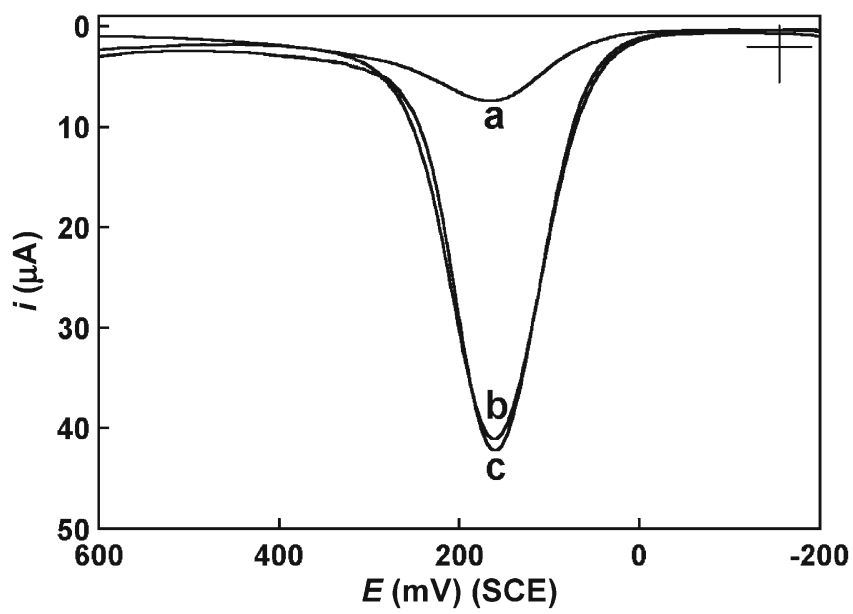

Figure 7. DPVs obtained at $\mathrm{GC} / \mathrm{LaHCF}$ electrode in $0.1 \mathrm{M}$ phosphate buffer containing $0.1 \mathrm{M} \mathrm{NaCl}$ (a) in the absence of DA and AA, (b) $5 \mu \mathrm{M}$ DA in the presence of $0.1 \mathrm{mM}$ AA and (c) $5 \mu \mathrm{M}$ DA in the absence of AA. Scan rate $=5 \mathrm{mV} \mathrm{s}^{-1}$. such as AA, nitrite, nitrate and other neurotransmitters metabolites. Owing to the higher concentrations, AA is an important interfering species in the biological systems. One useful strategy to eliminate AA, involves electrostatic repulsion by the anionic polymer, particularly Nafion (Nf) at the electrode surface due to its permselective behaviour. ${ }^{29,30}$ In the present study, in order to show selectivity towards DA oxidation at the modified electrode surface, the voltammetric behaviour was investigated in the presence of AA. Figure 7(a) shows the DPV recorded at the LaHCFmodified electrode in a solution containing $0.1 \mathrm{M}$ phosphate buffer and $0.1 \mathrm{M} \mathrm{NaCl}$. Figure 7(b) and (c) show the DPVs for DA oxidation in the presence (curve b) and in the absence of AA (curve c) at GC/LAHCF electrode. In the presence of AA, there is no significant change in the DA oxidation (figure 7b). Furthermore, LaHCF-modified electrode in the presence of $0.1 \mathrm{M} \mathrm{NaCl}$ would be an effective barrier towards AA electroxidation and thereby selective oxidation of DA is achieved.

\subsection{Analytical application}

Analytical application of LaHCF-modified electrode in the determination of DA is being extended to study real sample analysis such as dopamine hydrochloride injection solution (DHI). Exact concentration of DA in DHI injection solution is determined by the standard addition method (spike method) using GC/LaHCFmodified electrode and the results are summarized in table 1. Under the optimum conditions chosen, the DPV peak currents are linearly related to [DA] over the concentration range between $5.0 \times 10^{-8}$ and $5 \times$ $10^{-6} \mathrm{M}$ with a correlation coefficient of 0.992 (figure not shown). A detection limit of $10 \mathrm{nM}$ is estimated at a signal-to-noise ratio of 3 . The DA is repeatedly determined with duplicate samples and the relative standard deviation is found to be $7.5 \%$.

Table 1. Estimation of dopamine in DHI solution using GC/LaHCF-modified electrode. ${ }^{\text {a }}$

\begin{tabular}{lccccc}
\hline Sample & $\begin{array}{c}\text { DA content } \\
\text { DHI }(\mu \mathrm{M})\end{array}$ & $\begin{array}{c}\text { DA found } \\
(\mu \mathrm{M})(n=3)\end{array}$ & $\begin{array}{c}\text { DA spike } \\
(\mu \mathrm{M})\end{array}$ & $\begin{array}{c}\text { DA found } \\
(\mu \mathrm{M})\end{array}$ & $\begin{array}{c}\text { Mean recovery }(\%) \pm \\
\text { S.D. }(n=3)\end{array}$ \\
\hline 1 & 10 & 9.6 & 10 & 9.8 & $98.0 \pm 2.1$ \\
2 & 10 & 9.0 & 10 & 9.2 & $92.2 \pm 8.8$ \\
3 & 10 & 9.2 & 10 & 9.4 & $94.4 \pm 6.5$ \\
\hline
\end{tabular}

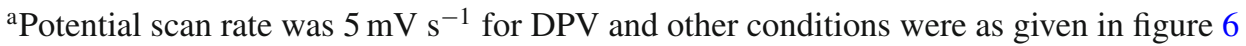

${ }^{\mathrm{b}}$ Average values of three determinations 


\section{Conclusion}

On GC electrode, the rare earth metal hexacyanoferrate, LaHCF $\left(\mathrm{Na}^{+} \mathrm{La}^{3+}\left[\mathrm{Fe}^{\mathrm{II}}(\mathrm{CN})_{6}\right]\right)$, has been successfully electrodeposited, which exhibits a diffusion controlled reaction mechanism. The highlight of this study is the promotion of electron mediation activity towards DA oxidation in phosphate buffer containing $0.1 \mathrm{M} \mathrm{NaCl}$ at the GC/LaHCF-modified electrode. Importantly, in the presence of interference such as AA, selective oxidation of DA is achieved in phosphate buffer containing $\mathrm{NaCl}$. Thus, the GC/LaHCF-modified electrode is found to be an excellent and satisfactory electrochemical read-out method for the neurotransmitter molecule such as DA with a detection limit in the submicromolar range.

\section{Acknowledgements}

Financial support from the Department of Science and Technology (DST), New Delhi, is acknowledged.

\section{References}

1. Scholz F and Meyer B 1998 In Electroanalytical chemistry A J Bard and I Rubinstein (eds) (New York: Marcel Dekker) vol. 20

2. Itaya K, Uchida I and Neff V D 1986 Acc. Chem. Res. 19162

3. Widmann A, Kahlert H and Prelevic I P 2002 Inorg. Chem. 415706

4. de Tacconi N R, Rajeshwar K and Lezna R O 2003 Chem. Mater. 153046

5. Ricci F and Palleschi G 2005 Biosens. Bioelectron. 21 389

6. Zen J-M, Kumar A S and Tsai D M 2003 Electroanalysis 151073

7. Vittal R and Gomathi H 2002 J. Phys. Chem. B106 10135

8. Lezna R O, Romagnoli R and de Taccon N R 2002 J. Phys. Chem. B106 3612

9. Liu S Q and Chen H Y 2002 J. Electroanal. Chem. 528 190 and references cited therein

10. Druten G M R V, Labbe E and Boncour V P 2000 J. Electroanal. Chem. 48731 and references cited therein

11. Jiang H-J, Huang X-H and Wang X-F 2003 J. Electroanal. Chem. $\mathbf{5 4 5} 83$

12. Cai C X, Xue K H and Xu S M 2000 J. Electroanal Chem. 486111

13. Xun Z Y, Cai C X and Xing W 2003 J. Electroanal. Chem. 54519

14. Chen S M and Peng K T 2003 J. Electroanal. Chem. 547 179
15. Golabi S M and Noor-Mohammadi F 1998 J. Solidstate Electrochem. 230

16. Cataldi T R I, de Benedetto G and Bianchini A 1999 J. Electroanal. Chem. 47142

17. Ohkoshi S, Fujishima A and Hashimoto K 1998 J. Am. Chem. Soc. 1205349

18. Wu P, Lu S and Cai C X 2004 J. Electroanal. Chem. 569 143

19. Wu P and Cai C X 2005 Chin. J. Chem. V23 127

20. Liu S Q, Chen Y and Chen H Y 2001 J. Electroanal. Chem. $\mathbf{5 0 2} 197$

21. Liu S Q, Chen Y and Chen H Y 2002 Electroanalysis 14 116

22. Wang G, Meng J, Liu H, Jiao S, Zhang W, Chen D and Fang B 2008 Electrochim. Acta 532837

23. Gonon F, Buda M and Cespuglio R 1980 Nature 286902

24. Adams R N 1976 Anal. Chem. 48 1128A

25. Sternson A W, Mccreery R and Feinberg B $1973 \mathrm{~J}$. Electroanal. Chem. $\mathbf{4 6} 313$

26. Zen J-M and Chen P-J 1997 Anal. Chem. 695087

27. Selvaraju T and Ramaraj R 2003 Electrochem. Commun. 5667

28. Dayton M A, Ewing A G and Wightman R M 1980 Anal. Chem. 522392

29. Mauritz K A and Moore R B 2004 Chem. Rev. 1044535

30. Selvaraju T and Ramaraj R 2005 J. Electroanal. Chem. $\mathbf{5 8 5} 290$

31. Chen T-W, Tsai T-H and Chen S-M 2010 ECS Trans. 33 141

32. Tsai T-H, Chen T-W, Chen S-M and Saraswathi R 2012 Russ. J. Electrochem. 48291

33. Xun Z-Y, Cai C-X and Lu T-H 2004 Electroanalysis 16 674

34. Farhadi K, Kheiri F and Golzan M 2008 J. Braz. Chem. Soc. 191405

35. Shervedani R K and Alinajafi-Najafabadi H A 2011 Int. J. Electrochem. $\mathbf{6 0 3 1 3 5} 11 \mathrm{pp}$

36. Prabakar S J R and Narayanan S S 2009 Electroanalysis 211481

37. Mashhadizadeh M H, Yousefi T and Golikand A N 2012 Electrochim. Acta $\mathbf{5 9} 321$

38. Noroozifar M, Khorasani-Motlagh M and Taheri A 2010 Talanta 801657

39. Hosseinzadeh R, Sabzi R E and Ghasemlu K 2009 Colloids Surf. B: Biointerf. 68213

40. Fang B, Shen R, Zhang C, Yuan H, Yao L and Wang G 2009 Electroanalysis 212680

41. Chen S-M 2002 J. Electroanal. Chem. 52129

42. Kulesza P J, Malik M A and Schmidt R 2000 J. Electroanal. Chem. 48757

43. Kulesza P J and Malik M A 1998 J. Phys. Chem. B102 1870

44. Malik M A, Miecznikowski K and Kulesza P 2000 Electrochim. Acta 453777

45. Malik M A, Horanyi G and Kulesza P J 1998 J. Electroanal. Chem. $\mathbf{4 5 2} 57$

46. Tian Y, Mao L, Okajima T and Ohsaka T 2004 Anal. Chem. 764162 